\title{
Review
}

\section{Cell reprogramming: expectations and challenges for chemistry in stem cell biology and regenerative medicine}

\author{
L Anastasia ${ }^{*, 1,2}$, G Pelissero $^{2}$, B Venerando $0^{1,2}$ and G Tettamanti ${ }^{2}$
}

The possibility of reprogramming adult somatic cells into pluripotent stem cells (iPSCs) has generated a renewed interest into stem cell research and promises to overcome several key issues, including the ethical concerns of using human embryonic stem cells and the difficulty of obtaining large numbers of adult stem cells (Belmonte et al., Nat Rev Genet, 2009). This approach is also not free from challenges like the mechanism of the reprogramming process, which has yet to be elucidated, and the warranties for safety of generated pluripotent cells, especially in view of their possible therapeutic use. Very recently, several new reprogramming methods have surfaced, which seem to be more appropriate than genetic reprogramming. Particularly, chemically induced pluripotent cells (CiPSs), obtained with recombinant proteins or small synthetic molecules, may represent a valid approach, simpler and possibly safer than the other ones.

Cell Death and Differentiation (2010) 17, 1230-1237; doi:10.1038/cdd.2010.14; published online 19 February 2010

Stem cells and cell reprogramming have generated an enormous interest in the past 2 years, since the generation of induced pluripotent stem cells (iPSCs) from mouse embryonic fibroblasts was first reported by Yamanaka and coworkers in 2006. ${ }^{1,2}$ In fact, it was shown that the forced expression of four defined factors (Oct3/4, Sox2, Klf4, and c-Myc) is able to reprogram a fraction of mouse embryonic fibroblasts into pluripotent cells, almost indistinguishable from bona fide embryonic stem cells (ESCs). Successively, human adult fibroblasts have also been reprogrammed to iPSCs by the same four factors, ${ }^{3-8}$ or by combinations of other factors, which included Nanog and Lin $28 .{ }^{9}$ Moreover, iPSCs cells have been generated also from other cell types including adult hepatocytes, gastric epithelial cells, and mesenchymal cells. ${ }^{4,10}$ However, it has been reported that iPSCs obtained from different adult cells possess a different teratoma-forming propensity in a cell transplantation therapy model using mouse secondary neurospheres differentiated from iPSCs, suggesting that it will be extremely important to elucidate this issue before future clinical applications. ${ }^{11}$ Nonetheless, these discoveries have generated an unprecedented deal of interest toward stem cell research, mostly for these reasons: (1) iPSCs generation does not require the use (and disruption) of embryos, thus it completely overcomes the ethical drawbacks associated to the use of human ESCs, (2) although iPSCs generation is technically still somewhat inefficient, once iPSCs colonies are formed, they can be expanded in vitro to large numbers, in contrast to adult stem cells, that normally possess very low self-renewal in vitro, and (3) iPSCs can be patient customized, because they can be generated from an easily accessible source, that is fibroblasts, obtainable from any individual (Figure 1). Therefore, it is not surprising that many leading research groups, which for many years have contributed to ES cells research, have now turned their attention to iPSCs, and some doubts have been posed about the future of 'normal ES cell research. $., 12,13$

Although iPSCs opened up a new era in stem cell research, this breakthrough discovery is accompanied by new challenges that need to be overcome to turn a 'proof of concept' into a new possible therapeutic tool. At this stage, there are several problems to be addressed: (1) the safety of the reprogramming process, ${ }^{11}$ that so far has been done mainly through a genetic manipulation of the cell; (2) the possible incomplete reprogramming, raising questions about the effective equivalence between iPS and ES cells; (3) the epigenetic differences between ES and iPS cells, which may cause, among other consequences, a different differentiation potential; and (4) the need of efficient methods to induce the differentiation of iPS (or ES) cells into the desired cell type, without undesired turnings, often leading into cancer. These major problems have been tackled in several ways, which will be outlined in this review. Actually, the primary concern about iPSCs is that they have been generated by transduction of somatic cells with retroviruses or lentiviruses, thus the

${ }^{1}$ Department of Medical Chemistry, Biochemistry and Biotechnology, University of Milan, Segrate, Milan, Italy and ${ }^{2}$ Laboratory of Stem Cells for Tissue Engineering, IRCCS Policlinico San Donato, San Donato, Milan, Italy

*Corresponding author: L Anastasia, Department of Medical Chemistry, Biochemistry and Biotechnology, University of Milan, L.I.T.A., Segrate, Milan, Italy and Laboratory of Stem Cells for Tissue Engineering, IRCCS Policlinico San Donato, San Donato, Milan, Italy. Tel: + 3902 52774674; Fax: + 3902 52774666;

E-mail: luigi.anastasia@unimi.it

Keywords: cell reprogramming; de-differentiation; induced pluripotent stem cells; reversine; combinatorial chemistry; chemically induced pluripotent stem cells (CiPSs) Abbreviations: iPSCs, induced pluripotent stem cells; GiPS, genetically induced pluripotent stem cells; CiPS, chemically induced pluripotent stem cells; FDA, Food and Drug Administration; SCNT, somatic cell nuclear transfer

Received 09.7.09; revised 30.12.09; accepted 19.1.10; Edited by RD Maria; published online 19.2.10 


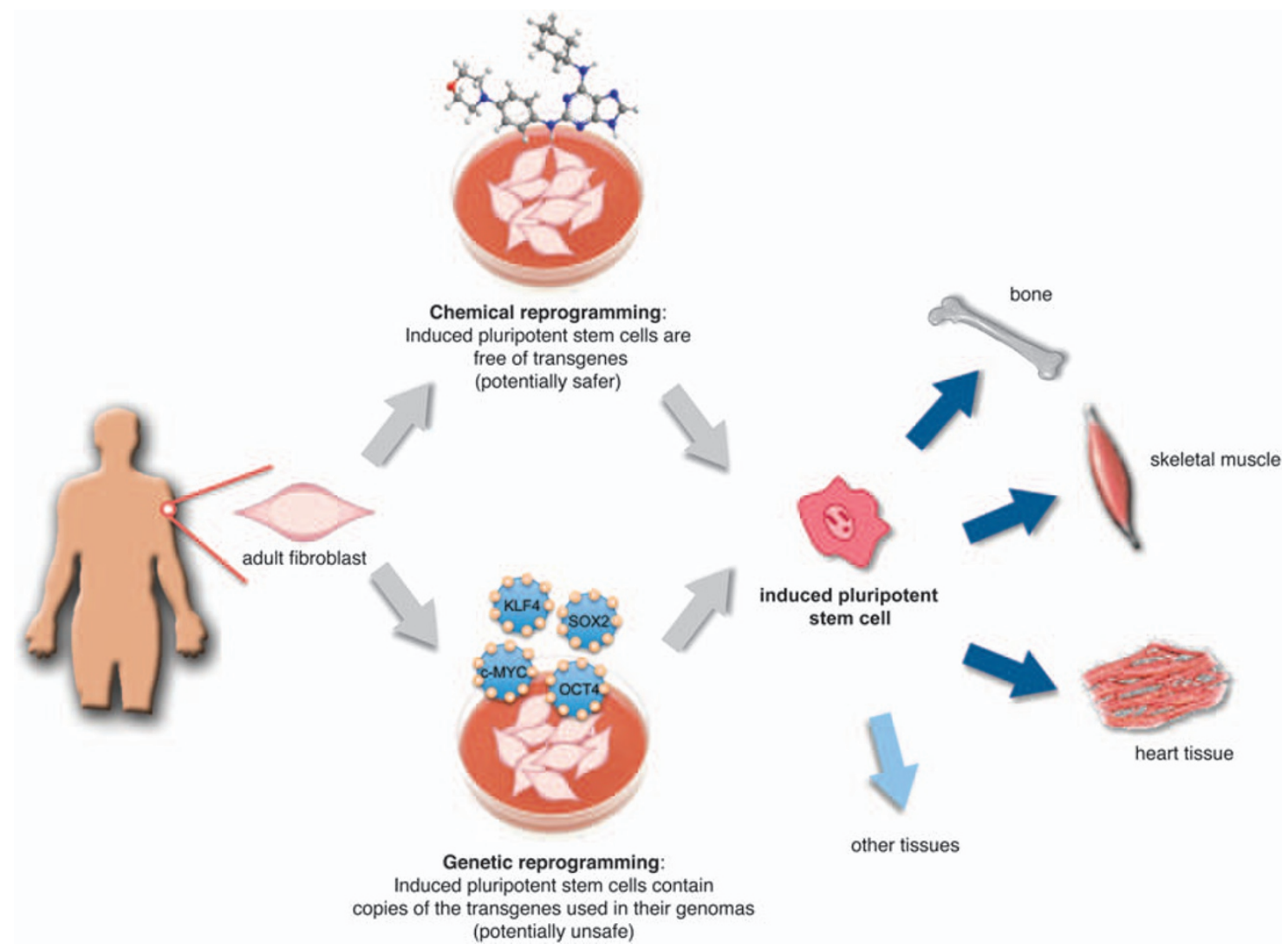

Figure 1 Cell reprogramming: a new source of patient-specific pluripotent cells for regenerative medicine and drug discovery.

transgenes used are integrated into the cell genome. Very recently, several approaches have been proposed to overcome this issue. In fact, iPSCs have been generated by transient expression of single nonviral polycistronic vectors, ${ }^{14,15}$ by a Cre/loxP recombination system, ${ }^{16}$ by the piggyBac (PB) transposon system, ${ }^{17,18}$ by nonintegrating episomal vectors, ${ }^{19}$ and by recombinant proteins. ${ }^{20}$ However, the possibility of reprogramming cells by a chemical approach, that is by treating them with appropriate de-differentiating drugs, has been auspicated by many authors. ${ }^{21,22}$ In fact, chemical induction/reprogramming has several intrinsic advantages over genetic manipulation: (1) timing, as drugs can usually reach their target(s) very quickly and selectively; (2) control, as the concentration of the drug can be easily varied to reach the desired effect in the most efficient way; (3) simplicity, as chemical treatments will allow a very simple tool, as compared with the use of retro- or lenti-vital systems; and (4) low cost, as new drugs, once identified, can be easily synthesized in large scale by consolidated methods. Actually, chemical modulation of differentiation is not a new approach. In fact, many synthetic and natural products have been extensively used over the past decades, long before the development of combinatorial chemistry and high-throughput screening. Among others, it was shown over a decade ago that retinoic acid and its derivatives could be used to induce mouse ES cells to express multiple phenotypes normally associated with neurons. ${ }^{23}$ Another molecule, 5-azacytidine, a potent DNA methylation inhibitor, was first synthesized over
40 years ago, ${ }^{24}$ and it was shown to have a wide range of antimetabolic activities when tested against cultured cancer cells and to be an effective chemotherapeutic agent for acute myelogenous leukemia. ${ }^{25}$ More recently, it has been shown that in vitro treatment with 5-azacytidine, even if not enough to generate mature cardiomyocytes, promotes the in vivo and in vitro commitment of bone marrow cells into cells that express muscle-specific proteins and genes and, at a very low rate, show spontaneous contractions. ${ }^{26}$

\section{A Chemical Boost to Stem Cell Research and Regenerative Medicine}

Organic chemistry and cell biology have been working together as a single discipline for centuries, giving rise to many discoveries that greatly contributed to the progress of scientific research. Then, at the beginning of the past century, they split-up and started to grow on separate tracks, as they developed into independent sciences. However, in the past few years, many organic chemists are turning their attention to biological systems, including stem cell biology. ${ }^{21,27}$ In particular, new tools developed in organic chemistry, as combinatorial synthesis and high-throughput screening have been extensively used in both basic biology and drug discovery. ${ }^{28}$ This approach, which was originated by the solid-phase synthesis of peptides introduced by Merrifield in $1963,{ }^{29}$ was greatly developed in the 1990 s. Modern combinatorial synthesis allows the generation of so-called 
'libraries' of compounds, each containing an average of 40-100 thousands compounds. In the last decade, almost all pharmaceutical companies have been screening libraries to find new drug candidates, many of which are currently under advanced clinical trials, or have been already released like sorafenib, a multikinase inhibitor for the treatment of advanced renal cancer, approved for clinical use by FDA. ${ }^{30}$ In any case, as documented in this review, high-throughput screening has allowed the identification of several new compounds, which appear to possess a remarkable potential for stem cell biology. ${ }^{27}$

\section{Chemistry and Cell Reprogramming}

The intricate process of cell differentiation, from ES cells to terminally differentiated somatic cells, has been depicted for years as a one-way multistep process. In fact, even in the case of tissue regeneration on damage, adult mammals can only use pre-existing progenitor cells, which are activated to proliferate and differentiate to replace the lost cells. On the other hand, a few examples coming from nature have puzzled scientists for several decades. For instance, amphibians like the salamander use a different mechanism for regeneration, because the stem cells used to repair the damage are generated in situ through the de-differentiation of adult cells. ${ }^{31}$ In fact, the salamander can fully regenerate its limbs by forming a so-called blastema, a mass of de-differentiated cells, which can proliferate and differentiate to regenerate the injured or even completely amputated body part. Several attempts have been made over the years to unleash the same de-differentiation process in mammalians, with the ultimate goal of generating stem cells from adult cells in vitro. ${ }^{32}$ These approaches include somatic cell nuclear transfer (SCNT, often referred to as somatic cloning), ${ }^{33-36}$ which not only raised numerous ethical debates, but so far has been shown to be too inefficient to be practicable. ${ }^{37}$ Other techniques include fusion of adult cells to ES cells ${ }^{38-40}$ and treatment of differentiated cells with newt blastema extracts, ${ }^{41}$ but they have yet to be further developed. At the same time, a different strategy has been quite successful, the so-called transdifferentiation process, which consist of the direct reprogramming of a somatic cell into a different cell type, possibly without going back and forth in the differentiation hierarchy. For example, pancreatic cells have been successfully converted into hepatocytes by treatment with a synthetic glucocorticoid, dexamethasone, ${ }^{42}$ or oligodendrocyte precursor cells could be reverted to multipotential neural stem cells, which could give rise to neurons and astrocytes, as well as to oligodendrocytes. ${ }^{43}$

Finally, a new chemical approach, which was pioneered by Schultz and coworkers, ${ }^{44}$ and further developed by Ding and coworkers, ${ }^{45,46}$ is the screening of combinatorial libraries of small molecules, with the ultimate goal of identifying target compounds that can induce the de-differentiation process. ${ }^{21}$ This method requires the design of very specific and quick screening assays that allow the identification of active compounds (see Figure 2 for a list of several small molecules successfully used in stem cell biology) from a pool of several thousands of random compounds. One initial screening by Schultz's group led to the identification of myoseverin, a synthetic purine that has been shown to induce the quantitative and reversible fission of multinucleated myotubes into mononucleated fragments. ${ }^{47}$ Myoseverin, together with other structurally related compounds, inhibited the polymerization of purified bovine tubuline in vitro. Both microtubule depolymerization activity and myotube disassembly were dependant on the presence of methoxy groups at the paraposition of both benzyl rings, whereas methylation at the N6 position abolished activity (Figure 2). Myoblasts, derived from myotubes by myoseverin addition, could proliferate and redifferentiate into myotubes, although the molecule irreversibly binds to cells. Moreover, it was shown that the molecule affects gene expression, as myogenic differentiation markers were downregulated, whereas genes associated with cell proliferation were upregulated. However, in histone $\mathrm{H} 1$ phosphorylation assays, it was found that myoseverin did not inhibit CDK1 activity, indicating a different mechanism of action from other bioactive 2,6,9-trisubstituted purines. ${ }^{48}$ Although the obtained myoblasts could not be further de-differentiated into stem cells (thus did not acquire pluripotency), this is, to the best of our knowledge, the first example of the reprogramming of a terminally differentiated cell by a synthetic small molecule. Successively, the same group designed a new high-throughput screen, and identified a new synthetic purine, which they named reversine, that could revert mouse proliferating myoblasts (C2C12) to a more undifferentiated state, as they could be converted into adipocytes and osteoblasts when treated with appropriate differentiating media. ${ }^{44}$ These results, came out 2 years before the report of iPSCs and generated mixed reactions from the scientific community, which at that time was posing questions about the feasibility of the de-differentiation process. Nevertheless, several successive independent studies showed the potential of reversine, even on an easily accessible cell source as dermal fibroblasts. ${ }^{49}$ In particular, our group reported that primary cultures of murine and human dermal fibroblasts, after reversine treatment, could be efficiently induced to differentiate into myocytes both in vitro and in vivo, in a mouse regeneration model. Moreover, reversine-treated fibroblasts could be induced to differentiate into smooth muscle and bone cells in vitro ${ }^{49}$ (Figure 3). These results showed the soundness of a chemical approach toward cell reprogramming, and stimulated further developments. In fact, it has been recently shown that reversine-treated myoblasts, even at submicromolar concentrations, can be induced to differentiate toward the neuroectodermal lineage.$^{50}$ Although reversine mechanism of action is still not fully understood, evidence seems to point to interactions with key proteins involved in cytoskeletal and cell shape remodeling, RNA export, degradation, folding, stress control, and ATP production. ${ }^{51}$ Moreover, reversine has been shown to inhibit MEK1, the nonmuscular myosin heavy chain (NMMII) and some Aurora kinases, ${ }^{52-54}$ leading some research groups to propose the use of the molecule as a new anti-cancer agent. ${ }^{55,56}$ As reversine seems to be a nonspecific kinase inhibitor (due to its core structure, a modified purine), it may be argued that unpredictable or undesirable off-target effects may be expected. ${ }^{57}$ This concern may be real, and it is safe to say that reversine can be considered a tool to understand the reprogramming mechanism. In fact, it has also been shown 
<smiles>COc1ccc(CNc2nc(NCc3ccc(OC)cc3)c3ncn(C(C)C)c3n2)cc1</smiles><smiles>CCCC(CCC)C(=O)O</smiles>

Valproic acid (cell reprogramming)<smiles>c1nc2c(NC3CCCCC3)nc(Nc3ccc(N4CCOCC4)cc3)nc2[nH]1</smiles>

Reversine (de-differentiation)<smiles>COC(=O)C1=C(C)NC(C)=C([N+](=O)[O-])C1c1ccccc1C(F)(F)F</smiles>

BayK8644 (generation of iPS)

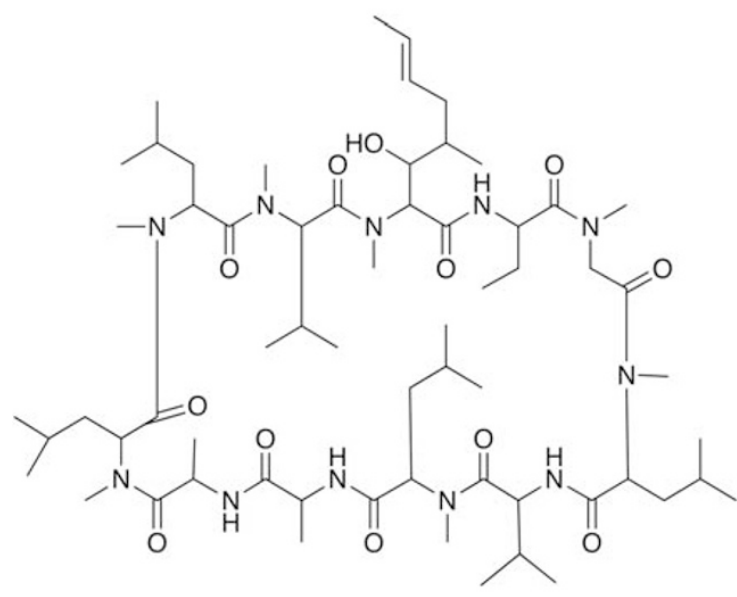

Cyclosporin A (cardiogenesis)<smiles>Nc1ncn([C@@H]2OC(CO)C(O)C2O)c(=O)n1</smiles>

5-Azacytidine (cell reprogramming)<smiles>COc1cc2nc(N3CCCN(C)CC3)nc(NC3CCN(Cc4ccccc4)CC3)c2cc1OC</smiles>

BIX 01294 (generation of iPS)

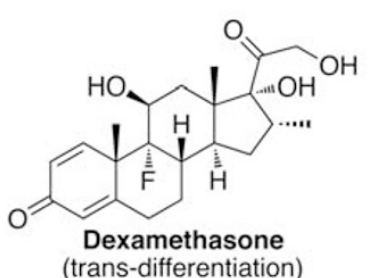
(trans-differentiation)<smiles>COc1ccc(Nc2nccc(NCCO)n2)cc1</smiles>

Cardiogenol C (cardiogenesis)<smiles>O=S(=O)(N/N=C/c1cc(Br)ccc1O)c1ccccc1</smiles>

Shz-1

(cardiogenesis)

Figure 2 Examples of small molecules used in stem cell biology for de-differentiation of adult cells or to pilot stem cell differentiation toward desired cell phenotypes.

that, at least in the case of $\mathrm{C} 2 \mathrm{C} 12$ cells, specific inhibition of both MEK1 and NMMII by other means, is sufficient to mimic reversine reprogramming. ${ }^{52}$

More recently, the discovery of iPSCs has shown that adult cells can be induced to go back all the way to a pluripotent ESlike state. Although a 'genetically driven' reprogramming process has been reproduced in several laboratories, little is known about the mechanisms involved in the induction. 1,58,59 However, very recent data obtained by several laboratories established a link between the reprogramming process and p53 pathway, showing that disabling p53, an essential tumorsuppressor protein, improves the efficiency of stem cell production. ${ }^{60-66}$ Moreover, as already pointed out, there are at least two major safety problems that need to be solved: (1) the process is very slow, thus culturing cells in vitro for several weeks may result in genetic alterations; (2) iPS are mostly generated by exogenous genetic manipulations, as the master genes are introduced by viral infection. Although a very recent report shows that iPSCs can be generated by transient technologies, without evidence of genomic integration, this possibility cannot be completely ruled out. ${ }^{67}$ It is in this scenario that a chemical approach may become crucial, and some initial results seem to suggest that we are quickly moving from what we may propose to call 'genetically induced' pluripotent cells (GiPS) to a new generation of 'chemically induced' pluripotent cells (CiPS). In fact, very recent studies reported the generation of iPS by combining genetic reprogramming and small molecules. ${ }^{46,68,69}$ In particular, it has been shown that the combination of two small molecules, BIX-01294, a known G9a histone methyltransferase inhibitor, ${ }^{70,71}$ and BayK8644, a L-channel calcium agonist, ${ }^{72}$ together with the transduction with Oct3/4 and Klf4, allows 

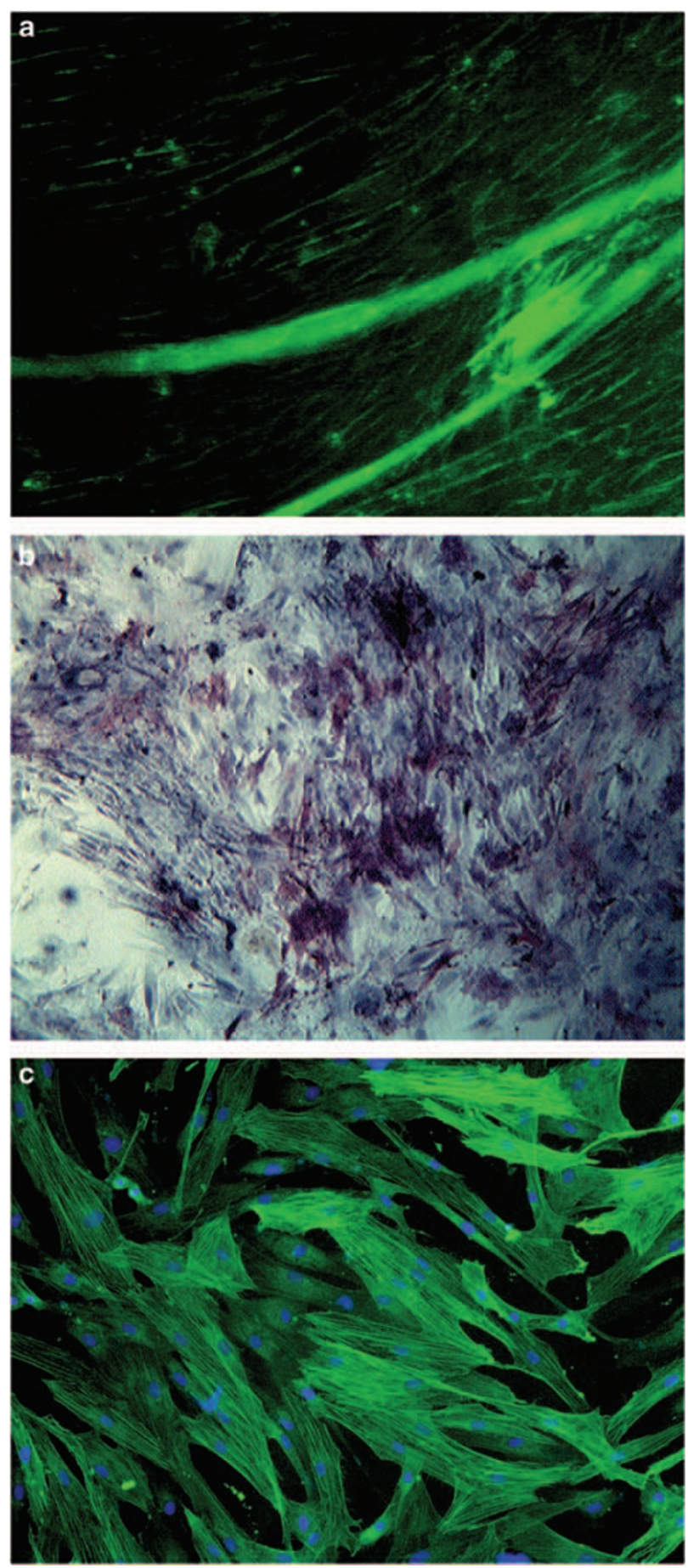

Figure 3 Reversine-treated human fibroblasts can be induced to differentiate into skeletal muscle (a) by co-culture with myoblasts, immunofluorescence reveals MHC positive myotubes in green, bone (b), alkaline phosphatase expressing cells stained in violet, and (c) smooth muscle, immunofluorescence reveals $\alpha$-actin positive cells in green by treatment with the appropriate differentiating media.

the reprogramming of mouse embryonic fibroblasts to iPSCs, ${ }^{68}$ although with a lower efficiency $(50 \%$ lower) as compared with transfection with the four factors OCT4/SOX2/ $\mathrm{KIf} 4 / \mathrm{c}-$ Myc. It is interesting to point out that BayK8644 does not directly modify the epigenetic status of the cell, in contrast to BIX and other small molecules known to affect cell reprogramming like valproic acid ${ }^{73}$ and 5 -azacytidine, ${ }^{74}$ which are known epigenetic drugs. This feature is very desirable for a candidate molecule to become a safe therapeutic drug. However, 5-azacytidine improves reprogramming efficiency by 10 -fold, whereas valproic acid by $>100$-fold. ${ }^{73}$ Furthermore, valproic acid can substitute for oncogene c-Myc in the reprogramming process, with an efficiency that is superior to that achieved with infection all four factors. ${ }^{73}$ More recently, iPSCs from adult rat cells were also generated by genetic reprogramming with lentivirus containing a cocktail of reprogramming factors, ${ }^{75}$ and concomitantly it was also reported that rat iPSCs could be obtained with small molecules, in combination with genetic reprogramming. ${ }^{46}$ These results are of great interest, as bona fide rat ES cells have been so far isolated with great difficulty, and they do not show true pluripotency. ${ }^{76-79}$ In fact, when rat iPSCs are generated by viral transfection with the four factors OCT4/SOX2/KIf4/ c-Myc, they quickly differentiate and lose ESC morphology, suggesting that conventional mESC medium conditions cannot maintain the pluripotent state. ${ }^{46}$ On the other hand, when rat iPSCs were cultured in the presence of a cocktail containing LIF, PD0325901 (a MEK inhibitor), A-83-01 (an inhibitor of the type 1 TGF $\beta$ receptor), and CHIR99021 (a GSK $3 \beta$ inhibitor), they could be maintained for $>30$ passages without differentiation or decreased proliferation. ${ }^{46}$ In a different study, it has been reported that the combination of other chemical inhibitors targeting FGF receptor, MEK and GSK3 enables efficient derivation and propagation of germline-competent ES cells from the rat. ${ }^{80}$ Very recently, another small molecule was identified by a combinatorial screening, kenpaullone, which could be used instead of Klf4 to generate iPSCs that are indistinguishable from murine ESCs. ${ }^{69}$ However, it has been shown that kenpaullone's activity does not result from its known role as a GSK-3 $\beta$ inhibitor, suggesting that the molecules function through a novel unknown mechanism. ${ }^{69}$

Taken together, all these results support the idea that small molecules are a crucial tool for the understanding of the intricate mechanisms that lead to cell reprogramming. Moreover, small drugs have already shown their potential to effectively replace viral transduction of key transcription factors such as SOX2, and KLF4, suggesting that we may not be that far from generating iPSCs by chemical induction alone.

\section{A Chemical Approach to Cell Differentiation}

ESCs differentiation. Finding a safe and efficient way of generating stem cells is only half way through solving the problem. In fact, once progenitors cells are generated, it is crucial to have very selective and high-yielding methods to pilot their differentiation toward the desired cell phenotype. ES cells can be arguably considered the best starting point, because they possess pluripotency, as compared with adult stem cells that are only multipotent, because they normally have limited potential. However, ES cells, because of their tremendous potency, are difficult to control, as they spontaneously tend to differentiate into several cell types. Nevertheless, a number of successful differentiation approaches have been developed over the years, with 
increasingly successful results, as thoroughly summarized recently. ${ }^{81}$ One of the main problems, which has yet to be fully solved, is that even when induced to differentiate, some ES cells remain undifferentiated and may result in the formation of teratomas. Thus, ES cells cannot be directly used for therapy, but they need to be pre-induced to differentiate in vitro, making sure to leave undifferentiated cells behind. In fact, to date, no human clinical trials have been approved yet, due to safety concerns, including the widely announced multicenter clinical trial by Geron (http:// www.geron.com) for grade A subacute thoracic spinal cord injuries, which has been put on hold by the FDA. Moreover, ES cells need to be grown in the presence of feeder cells and/or extremely expensive cocktails of cytokines and growth factors. To further complicate the picture, it has been shown that human ES cells respond to extrinsic signals differently from mouse ES cell, ${ }^{82,83}$ and are more similar to mouse epiSC (post-implantation epiblast-derived stem cells) than mouse ES cells. ${ }^{84}$ Thus, some differentiation strategies developed for mouse ES cells may not be directly extendable to human ES cells. At this stage, small molecules may have a primary function in the development of new strategies for human ES determination and differentiation. Undoubtedly, it would be really desirable to find small molecules that will replace or increase the efficacy of known key factors, including growth factors, cytokines, and WNT signaling pathway ${ }^{85}$ proteins. Several successful examples have already been reported. For instance, mouse ES cells have been induced to differentiate into spinal progenitor cells, and subsequently into motor neurons, with retinoic acid and the small molecule Hh-Ag1.3, agonist of Shh signaling. ${ }^{86}$ In a different study, a phenotypic cell-based screen of a combinatorial chemical library for the activation of the rat atrial natriuretic factor led to the identification of a class of diaminopyrimidine compounds, cardiogenol $A-D$, which could selectively induce mouse ES cells to differentiate into cardiomyocytes, ${ }^{87}$ although the mechanism of action is still unknown, and no further studies have been reported on this molecule. Nevertheless, it was reported that when mouse embryonic carcinoma cells (P19) were treated with Cardiogenol $\mathrm{C}$, they differentiated into beating cardiomyocytes in vitro, with $\sim 90 \%$ of cells staining positive for MEF2 and Nkx2.5. ${ }^{87}$ More recently, it was shown that human ESC-derived embryoid bodies, which after induction with combinations of activin A, bone morphogenetic protein 4 , basic fibroblast growth factor, vascular endothelial growth factor, and dickkopf homolog 1 in serum-free media, generate a KDR(low)/C-KIT(CD117)(neg) population that displays cardiac, endothelial, and vascular smooth muscle potential in vitro and, after transplantation, in vivo. ${ }^{88}$ Very recently, mouse cardiac progenitor cells could be derived from ES cells with high efficiency by addition of cyclosporin A to embryoid bodies. ${ }^{89}$ Moreover, these cardiac progenitors, transplanted in a chronic myocardial infarction model of rat, successfully differentiated into cardiomyocytes and integrated in the infarcted heart. Recently, in a screen of 4000 compounds, two cell-permeable small molecules were identified that direct differentiation of ESCs into the endodermal lineage. ${ }^{90}$ These compounds induce nearly $80 \%$ of ESCs to form definitive endoderm, a higher efficiency than that achieved by Activin $A$ or Nodal, commonly used protein inducers of endoderm. Altogether, these results show that a chemical approach to stem cell differentiation has started to become very effective, as many chemicals are emerging as potentially good (and cheaper) alternatives to growth factors.

Adult stem cells differentiation. Adult stem cells, differently than ES cells, are only multipotent, because they can normally be differentiated into a limited number of cell types, usually inherent to the tissue where they reside. Therefore, they are considered a safer starting point as compared with ES cells, particularly because they are not prone to form teratomas as in the case of ES cells. Moreover, adult stem cells do not encounter the same ethical obstacles of ES cells, thus explaining their faster development, as confirmed by $\mathrm{NIH}$ database (http://www.clinicaltrial.gov), which lists over a thousand adult stem cells-connected ongoing clinical trials. Indeed, although thousands of successful differentiations have been reported in the literature, especially in the case of mesenchymal stem cells, ${ }^{91}$ we are still far from highly efficient differentiation methods, as it would be required for an effective therapeutic tool. ${ }^{92,93}$ In fact, although each different type of adult stem cell should be considered alone, there are some general problems associated to their use: (1) they usually can be obtained in very small numbers from adult individuals; (2) they can only be grown for a limited number of passages in vitro before losing their differentiation potential; and (3) the yields of differentiation are often too low to be practical for a therapeutic use. As in the case of ES cells, differentiation of adult stem cells is obtained ex vivo with cocktails of growth factors and signaling molecules. Furthermore, some recently discovered adult stem cells, like neural stem cells ${ }^{94}$ or cardiac progenitor cells, ${ }^{95}$ possess a very limited turnover, thus new chemically defined growth conditions have been recently developed. ${ }^{96}$ To give a very interesting recent example of chemically induced differentiation of adult stem cells, it has been reported that a synthetic sulfonylhydrazone (Shz1), found in a combinatorial library screen for the activation of NKX2.5, can trigger cardiac differentiation of human mobilized peripheral blood mononuclear cells, and these in vitro generated human cardiac cells can engraft into a rat heart in proximity to an experimental injury, improving cardiac function. ${ }^{97}$ The improvement of current differentiation methods is mandatory, and cell-based phenotypic assays and/or pathway screens of synthetic molecules promise to provide new possibilities for more selective and efficient differentiations. ${ }^{21,27,96}$

\section{Conclusions and Perspectives}

The generation of pluripotent cells from adult cells is undoubtedly a keystone achievement in stem cell biology. This discovery has allowed the scientific community to overcome one of the most debated ethical issues of our times, the disruption of embryos for the generation of human ES cells. This new fascinating path has already shown its potential, but at the same time, it already posed new challenges to scientist around the world. A chemical approach for the generation of stem cells from adult cells has been invoked as a safer and more convenient alternative to genetic 
manipulation, which is widely used to generate iPSCs today. Very recent advances have already shown that the goal is getting closer, ${ }^{71}$ and we may envision the possibility of easily generating stem cells customized to the patient, which will open new perspective in both regenerative medicine and drug discovery. In fact, the 'short-term' application of iPSCs may be to use them for drug discovery or toxicology screens in vitro. Moreover, they can allow the generation of disease models in culture, starting from patient cells, which would allow to test patient-specific therapies. We are at the beginning of a new exciting era in stem cell biology, there are great expectations and a remarkable potential ahead of us, and the best has yet to come.

\section{Conflict of interest}

\section{The authors declare no conflict of interest.}

1. Belmonte JC, Ellis J, Hochedlinger K, Yamanaka S. Induced pluripotent stem cells and reprogramming: seeing the science through the hype. Nat Rev Genet 2009; 10: 878-883.

2. Takahashi K, Yamanaka S. Induction of pluripotent stem cells from mouse embryonic and adult fibroblast cultures by defined factors. Cell 2006; 126: 663-676.

3. Lowry WE, Richter L, Yachechko R, Pyle AD, Tchieu J, Sridharan R et al. Generation of human induced pluripotent stem cells from dermal fibroblasts. Proc Natl Acad Sci USA 2008; 105: 2883-2888.

4. Park IH, Zhao R, West JA, Yabuuchi A, Huo H, Ince TA et al. Reprogramming of human somatic cells to pluripotency with defined factors. Nature 2008; 451: 141-146.

5. Takahashi K, Tanabe K, Ohnuki M, Narita M, Ichisaka T, Tomoda K et al. Induction of pluripotent stem cells from adult human fibroblasts by defined factors. Cell 2007; 131: 861-872.

6. Wernig M, Meissner A, Foreman R, Brambrink T, Ku M, Hochedlinger $\mathrm{K}$ et al. In vitro reprogramming of fibroblasts into a pluripotent ES-cell-like state. Nature 2007; 448: 318-324.

7. Wernig M, Zhao JP, Pruszak J, Hedlund E, Fu D, Soldner F et al. Neurons derived from reprogrammed fibroblasts functionally integrate into the fetal brain and improve symptoms of rats with Parkinson's disease. Proc Natl Acad Sci USA 2008; 105: 5856-5861.

8. Okita K, Ichisaka T, Yamanaka S. Generation of germline-competent induced pluripotent stem cells. Nature 2007; 448: 313-317.

9. Yu J, Vodyanik MA, Smuga-Otto K, Antosiewicz-Bourget J, Frane JL, Tian S et al. Induced pluripotent stem cell lines derived from human somatic cells. Science 2007; 318: 1917-1920.

10. Aoi T, Yae K, Nakagawa M, Ichisaka T, Okita K, Takahashi K et al. Generation of pluripotent stem cells from adult mouse liver and stomach cells. Science 2008; 321: 699-702.

11. Miura $\mathrm{K}, \mathrm{Okada} \mathrm{Y}, \mathrm{Aoi} \mathrm{T}$, Okada $\mathrm{A}$, Takahashi $\mathrm{K}$, Okita $\mathrm{K}$ et al. Variation in the safety of induced pluripotent stem cell lines. Nat Biotechnol 2009; 27: 743-745.

12. Gottweis H, Minger S. iPS cells and the politics of promise. Nat Biotechnol 2008; 26 : 271-272.

13. Vogel G, Holden C. Developmental biology. Field leaps forward with new stem cell advances. Science 2007; 318: 1224-1225.

14. Gonzalez F, Barragan Monasterio M, Tiscornia G, Montserrat Pulido N, Vassena R, Batlle Morera $L$ et al. Generation of mouse-induced pluripotent stem cells by transient expression of a single nonviral polycistronic vector. Proc Natl Acad Sci USA 2009; 106: 8918-8922.

15. Chang CW, Lai YS, Pawlik KM, Liu K, Sun CW, Li C et al. Polycistronic lentiviral vector for 'hit and run' reprogramming of adult skin fibroblasts to induced pluripotent stem cells. Stem Cells 2009; 27: 1042-1049.

16. Soldner F, Hockemeyer D, Beard C, Gao Q, Bell GW, Cook EG et al. Parkinson's disease patient-derived induced pluripotent stem cells free of viral reprogramming factors. Cell 2009; 136: 964-977.

17. Woltjen K, Michael IP, Mohseni $P$, Desai R, Mileikovsky M, Hamalainen R et al. piggyBac transposition reprograms fibroblasts to induced pluripotent stem cells. Nature 2009; 458: 766-770.

18. Kaji K, Norrby K, Paca A, Mileikovsky M, Mohseni P, Woltjen K. Virus-free induction of pluripotency and subsequent excision of reprogramming factors. Nature 2009; 458 : 771-775.

19. Yu J, Hu K, Smuga-Otto K, Tian S, Stewart R, Slukvin II et al. Human induced pluripotent stem cells free of vector and transgene sequences. Science 2009; 324: 797-801.

20. Zhou H, Wu S, Joo JY, Zhu S, Han DW, Lin T et al. Generation of induced pluripotent stem cells using recombinant proteins. Cell Stem Cell 2009; 4: 381-384.

21. Ding S, Schultz PG. A role for chemistry in stem cell biology. Nat Biotechnol 2004; 22 : 833-840.

22. Yamanaka S. A fresh look at iPS cells. Cell 2009; 137: 13-17.
23. Bain G, Kitchens D, Yao M, Huettner JE, Gottlieb DI. Embryonic stem cells express neuronal properties in vitro. Dev Biol 1995; 168: 342-357.

24. Sorm F, Piskala A, Cihak A, Vesely J. 5-Azacytidine, a new, highly effective cancerostatic. Experientia 1964; 20: 202-203.

25. Christman JK. 5-Azacytidine and 5-aza-2'-deoxycytidine as inhibitors of DNA methylation: mechanistic studies and their implications for cancer therapy. Oncogene 2002; 21: 5483-5495.

26. Burlacu A. Can 5-azacytidine convert the adult stem cells into cardiomyocytes? A brief overview. Arch Physiol Biochem 2006; 112: 260-264.

27. Xu Y, Shi Y, Ding S. A chemical approach to stem-cell biology and regenerative medicine. Nature 2008; 453: 338-344.

28. Newman DJ, Cragg GM. Natural products as sources of new drugs over the last 25 years. J Nat Prod 2007; 70: 461-477.

29. Merrifield RB. Solid phase peptide synthesis. I. The synthesis of a tetrapeptide. J Am Chem Soc 1963; 85: 2149-2154.

30. $\mathrm{Ng} \mathrm{R}$, Chen EX. Sorafenib (BAY 43-9006): review of clinical development. Curr Clin Pharmacol 2006; 1: 223-228.

31. Brockes JP. Amphibian limb regeneration: rebuilding a complex structure. Science 1997; 276: 81-87.

32. Gurdon JB, Melton DA. Nuclear reprogramming in cells. Science 2008; 322 : 1811-1815.

33. Wilmut I, Schnieke AE, McWhir J, Kind AJ, Campbell KH. Viable offspring derived from fetal and adult mammalian cells. Nature 1997; 385: 810-813.

34. McLaren A. Cloning: pathways to a pluripotent future. Science 2000; 288: 1775-1780.

35. Hochedlinger K, Jaenisch R. Nuclear reprogramming and pluripotency. Nature 2006; 441: 1061-1067.

36. Blelloch R, Wang Z, Meissner A, Pollard S, Smith A, Jaenisch R. Reprogramming efficiency following somatic cell nuclear transfer is influenced by the differentiation and methylation state of the donor nucleus. Stem Cells 2006; 24: 2007-2013.

37. Kennedy D. Editorial retraction. Science 2006; 311: 335.

38. Do JT, Scholer HR. Nuclei of embryonic stem cells reprogram somatic cells. Stem Cells 2004; 22: 941-949.

39. Ying QL, Nichols J, Evans EP, Smith AG. Changing potency by spontaneous fusion. Nature 2002; 416: 545-548.

40. Cowan CA, Atienza J, Melton DA, Eggan K. Nuclear reprogramming of somatic cells after fusion with human embryonic stem cells. Science 2005; 309: 1369-1373.

41. McGann CJ, Odelberg SJ, Keating MT. Mammalian myotube dedifferentiation induced by newt regeneration extract. Proc Natl Acad Sci USA 2001; 98: 13699-13704.

42. Shen CN, Slack JM, Tosh D. Molecular basis of transdifferentiation of pancreas to liver. Nat Cell Biol 2000; 2: 879-887.

43. Kondo T, Raff M. Oligodendrocyte precursor cells reprogrammed to become multipotential CNS stem cells. Science 2000; 289: 1754-1757.

44. Chen S, Zhang Q, Wu X, Schultz PG, Ding S. Dedifferentiation of lineage-committed cells by a small molecule. J Am Chem Soc 2004; 126: 410-411.

45. Chen S, Do JT, Zhang Q, Yao S, Yan F, Peters EC et al. Self-renewal of embryonic stem cells by a small molecule. Proc Natl Acad Sci USA 2006; 103: 17266-17271.

46. Li W, Wei W, Zhu S, Zhu J, Shi Y, Lin T et al. Generation of rat and human induced pluripotent stem cells by combining genetic reprogramming and chemical inhibitors. Cell Stem Cell 2008; 4: 16-19.

47. Rosania GR, Chang YT, Perez O, Sutherlin D, Dong H, Lockhart DJ et al. Myoseverin, a microtubule-binding molecule with novel cellular effects. Nat Biotechnol 2000; 18: 304-308.

48. Chang YT, Gray NS, Rosania GR, Sutherlin DP, Kwon S, Norman TC et al. Synthesis and application of functionally diverse 2,6,9-trisubstituted purine libraries as CDK inhibitors. Chem Biol 1999; 6: 361-375.

49. Anastasia L, Sampaolesi M, Papini N, Oleari D, Lamorte G, Tringali C et al. Reversinetreated fibroblasts acquire myogenic competence in vitro and in regenerating skeletal muscle. Cell Death Differ 2006; 13: 2042-2051.

50. Lee EK, Bae GU, You JS, Lee JC, Jeon YJ, Park JW et al. Reversine increases the plasticity of lineage-committed cells toward neuroectodermal lineage. J Biol Chem 2009; 284: 2891-2901.

51. Fania C, Anastasia L, Vasso M, Papini N, Capitanio D, Venerando B et al. Proteomic signature of reversine-treated murine fibroblasts by 2-D difference gel electrophoresis and MS: possible associations with cell signalling networks. Electrophoresis 2009; 30: 2193-2206.

52. Chen S, Takanashi S, Zhang Q, Xiong W, Zhu S, Peters EC et al. Reversine increases the plasticity of lineage-committed mammalian cells. Proc Natl Acad Sci USA 2007; 104: 10482-10487.

53. Shan SW, Tang MK, Chow PH, Maroto M, Cai DQ, Lee KK. Induction of growth arrest and polycomb gene expression by reversine allows $\mathrm{C} 2 \mathrm{C} 12$ cells to be reprogrammed to various differentiated cell types. Proteomics 2007; 7: 4303-4316.

54. Amabile G, D'Alise AM, lovino M, Jones P, Santaguida S, Musacchio A et al. The Aurora B kinase activity is required for the maintenance of the differentiated state of murine myoblasts. Cell Death Differ 2009; 16: 321-330.

55. Hsieh TC, Traganos F, Darzynkiewicz Z, Wu JM. The 2,6-disubstituted purine reversine induces growth arrest and polyploidy in human cancer cells. Int J Oncol 2007; 31: $1293-1300$. 
56. D'Alise AM, Amabile G, lovino M, Di Giorgio FP, Bartiromo M, Sessa F et al. Reversine, novel Aurora kinases inhibitor, inhibits colony formation of human acute myeloid leukemia cells. Mol Cancer Ther 2008; 7: 1140-1149.

57. Li JW, Vederas JC. Drug discovery and natural products: end of an era or an endless frontier? Science 2009; 325: 161-165.

58. Scheper W, Copray S. The molecular mechanism of induced pluripotency: a two-stage switch. Stem Cell Rev Rep 2009: 204-223.

59. Jaenisch R, Young R. Stem cells, the molecular circuitry of pluripotency and nuclear reprogramming. Cell 2008; 132: 567-582.

60. Banito A, Rashid ST, Acosta JC, Li S, Pereira CF, Geti I et al. Senescence impairs successful reprogramming to pluripotent stem cells. Genes Dev 2009; 23: 2134-2139.

61. Hong $\mathrm{H}$, Takahashi $\mathrm{K}$, Ichisaka T, Aoi T, Kanagawa O, Nakagawa M et al. Suppression of induced pluripotent stem cell generation by the p53-p21 pathway. Nature 2009; 460 1132-1135.

62. Utikal J, Polo JM, Stadtfeld M, Maherali N, Kulalert W, Walsh RM et al. Immortalization eliminates a roadblock during cellular reprogramming into iPS cells. Nature 2009; 460 $1145-1148$.

63. Marion RM, Strati K, Li H, Murga M, Blanco R, Ortega S et al. A p53-mediated DNA damage response limits reprogramming to ensure iPS cell genomic integrity. Nature 2009; 460: $1149-1153$.

64. Li H, Collado M, Villasante A, Strati K, Ortega S, Canamero M et al. The Ink4/Arf locus is a barrier for iPS cell reprogramming. Nature 2009; 460: 1136-1139.

65. Kawamura T, Suzuki J, Wang YV, Menendez S, Morera LB, Raya A et al. Linking the $p 53$ tumour suppressor pathway to somatic cell reprogramming. Nature 2009; 460: 1140-1144

66. Zhao $Y$, Yin X, Qin $\mathrm{H}$, Zhu F, Liu H, Yang W et al. Two supporting factors greatly improve the efficiency of human iPSC generation. Cell Stem Cell 2008; 3: 475-479.

67. Okita K, Nakagawa M, Hyenjong H, Ichisaka T, Yamanaka S. Generation of mouse induced pluripotent stem cells without viral vectors. Science 2008; 322: 949-953.

68. Shi Y, Desponts C, Do JT, Hahm HS, Scholer HR, Ding S. Induction of pluripotent stem cells from mouse embryonic fibroblasts by Oct4 and Klf4 with small-molecule compounds. Cell Stem Cell 2008; 3: 568-574

69. Lyssiotis CA, Foreman RK, Staerk J, Garcia M, Mathur D, Markoulaki S et al. Reprogramming of murine fibroblasts to induced pluripotent stem cells with chemical complementation of Klf4. Proc Natl Acad Sci USA 2009; 106: 8912-8917.

70. Kubicek S, O'Sullivan RJ, August EM, Hickey ER, Zhang Q, Teodoro ML et al. Reversal of H3K9me2 by a small-molecule inhibitor for the G9a histone methyltransferase. $\mathrm{Mol} \mathrm{Cell}$ 2007; 25: 473-481.

71. Shi Y, Do JT, Desponts C, Hahm HS, Scholer HR, Ding S. A combined chemical and genetic approach for the generation of induced pluripotent stem cells. Cell Stem Cell 2008; 2: $525-528$.

72. Schramm M, Thomas G, Towart R, Franckowiak G. Novel dihydropyridines with positive inotropic action through activation of Ca2+ channels. Nature 1983: 303: 535-537.

73. Huangfu D, Maehr R, Guo W, Eijkelenboom A, Snitow M, Chen AE et al. Induction of pluripotent stem cells by defined factors is greatly improved by small-molecule compounds. Nat Biotechnol 2008: 26: 795-797.

74. Mikkelsen TS, Hanna J, Zhang X, Ku M, Wernig M, Schorderet $P$ et al. Dissecting direc reprogramming through integrative genomic analysis. Nature 2008; 454: 49-55.

75. Liao J, Cui C, Chen S, Ren J, Chen J, Gao Y et al. Generation of induced pluripotent stem cell lines from adult rat cells. Cell Stem Cell 2009; 4: 11-15.

76. Demers SP, Yoo JG, Lian L, Therrien J, Smith LC. Rat embryonic stem-like (ES-like) cells can contribute to extraembryonic tissues in vivo. Cloning Stem Cells 2007; 9: $512-522$.
77. Ruhnke M, Ungefroren H, Zehle G, Bader M, Kremer B, Fandrich F. Long-term culture and differentiation of rat embryonic stem cell-like cells into neuronal, glial, endothelial, and hepatic lineages. Stem Cells 2003; 21: 428-436.

78. Schulze $M$, Ungefroren $H$, Bader $M$, Fandrich $F$. Derivation, maintenance, and characterization of rat embryonic stem cells in vitro. Methods Mol Biol 2006; 329: 45-58.

79. Ueda S, Kawamata M, Teratani T, Shimizu T, Tamai Y, Ogawa H et al. Establishment of rat embryonic stem cells and making of chimera rats. PLOS ONE 2008; 3: e2800.

80. Buehr M, Meek S, Blair K, Yang J, Ure J, Silva J et al. Capture of authentic embryonic stem cells from rat blastocysts. Cell 2008; 135: 1287-1298.

81. Murry CE, Keller G. Differentiation of embryonic stem cells to clinically relevant populations: lessons from embryonic development. Cell 2008; 132: 661-680.

82. Vallier L, Alexander M, Pedersen RA. Activin/nodal and FGF pathways cooperate to maintain pluripotency of human embryonic stem cells. J Cell Sci 2005; 118 (Part 19): 4495-4509.

83. Ying QL, Nichols J, Chambers I, Smith A. BMP induction of Id proteins suppresses differentiation and sustains embryonic stem cell self-renewal in collaboration with STAT3. Cell 2003; 115: 281-292.

84. Tesar PJ, Chenoweth JG, Brook FA, Davies TJ, Evans EP, Mack DL et al. New cell lines from mouse epiblast share defining features with human embryonic stem cells. Nature 2007; 448: 196-199.

85. Rijsewijk F, Schuermann M, Wagenaar E, Parren P, Weigel D, Nusse R. The Drosophila homolog of the mouse mammary oncogene int- 1 is identical to the segment polarity gene wingless. Cell 1987; 50: 649-657.

86. Wichterle $\mathrm{H}$, Lieberam I, Porter JA, Jessell TM. Directed differentiation of embryonic stem cells into motor neurons. Cell 2002; 110: 385-397.

87. Wu X, Ding S, Ding Q, Gray NS, Schultz PG. Small molecules that induce cardiomyogenesis in embryonic stem cells. J Am Chem Soc 2004; 126: 1590-1591.

88. Yang L, Soonpaa MH, Adler ED, Roepke TK, Kattman SJ, Kennedy M et al. Human cardiovascular progenitor cells develop from a KDR+ embryonic-stem-cell-derived population. Nature 2008; 453: 524-528.

89. Yan P, Nagasawa A, Uosaki H, Sugimoto A, Yamamizu K, Teranishi M et al. Cyclosporin-A potently induces highly cardiogenic progenitors from embryonic stem cells. Biochem Biophys Res Commun 2009; 379: 115-120.

90. Borowiak M, Maehr R, Chen S, Chen AE, Tang W, Fox JL et al. Small molecules efficiently direct endodermal differentiation of mouse and human embryonic stem cells. Cell Stem Cell 2009; 4: 348-358.

91. Friedenstein AJ, Gorskaja JF, Kulagina NN. Fibroblast precursors in normal and irradiated mouse hematopoietic organs. Exp Hematol 1976; 4: 267-274.

92. Summer R, Fine A. Mesenchymal progenitor cell research: limitations and recommendations. Proc Am Thorac Soc 2008; 5: 707-710.

93. Phinney DG, Prockop DJ. Concise review: mesenchymal stem/multipotent stromal cells: the state of transdifferentiation and modes of tissue repair-current views. Stem Cells 2007; 25: 2896-2902.

94. Okano H, Sakaguchi M, Ohki K, Suzuki N, Sawamoto K. Regeneration of the central nervous system using endogenous repair mechanisms. J Neurochem 2007; 102 $1459-1465$

95. Laflamme MA, Murry CE. Regenerating the heart. Nat Biotechnol 2005; 23: 845-856.

96. Sakurada K, McDonald FM, Shimada F. Regenerative medicine and stem cell based drug discovery. Angew Chem Int Ed Engl 2008; 47: 5718-5738.

97. Sadek H, Hannack B, Choe E, Wang J, Latif S, Garry MG et al. Cardiogenic smal molecules that enhance myocardial repair by stem cells. Proc Natl Acad Sci USA 2008; 105: 6063-6068. 